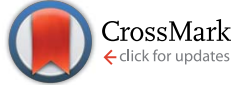

Cite this: RSC Adv., 2017, 7, 9596

Received 18th November 2016 Accepted 24th January 2017

DOI: 10.1039/c6ra26984b

rsc.li/rsc-advances

\section{The photovoltaic effect in a [001] orientated ZnO thin film and its physical mechanism $\uparrow$}

\author{
Bin Liu, $\dot{t}^{a}$ Jinlei Wang,,$^{a}$ Cuijin Pei, ${ }^{a}$ Lichao Ning, ${ }^{b}$ Lijuan Cheng, ${ }^{a}$ Congjie Zhang, ${ }^{b}$ \\ Heqing Yang ${ }^{\star a}$ and Shengzhong (Frank) Liü
}

We report a new type of photovoltaic effect. The photovoltaic device was constructed using a [001] orientated wurtzite $\mathrm{ZnO}$ thin film synthesized by heating $\mathrm{Zn}\left(\mathrm{NO}_{3}\right)_{2}$ solution. The open-circuit voltage $\left(V_{\text {oc }}\right)$ and short-circuit current $\left(I_{\mathrm{sc}}\right)$ of the $\mathrm{ZnO}$ photovoltaic device are $0.16 \mathrm{mV}$ and $0.25 \mu \mathrm{A}$, respectively, under $365 \mathrm{~nm}$ ultraviolet lamp (3 W) illumination. Current rectification across the top and bottom planes of the $\mathrm{ZnO}$ thin film was observed. The photovoltaic and rectifying properties of the $\mathrm{ZnO}$ thin film are related to the magnitude of the $\mathrm{TC}(002)$. An internal electric field is produced in the $\mathrm{ZnO}$ film by spontaneous polarization in the [001] direction. The presence of the internal electric field is the fundamental physical basis of the photovoltaic effect, and a new physical mechanism of photon-toelectron conversion is proposed. The electrostatic potential provides a driving force for flow of the photogenerated electrons and holes in the semiconductor and in an external load, and thus the phototo-electron conversion is achieved. Our result suggests thin film texturing as a strategy to develop photovoltaic devices beyond $\mathrm{p}-\mathrm{n}$ junction. In addition, the photo-to-electron conversion model provides new insights into the understanding of the photovoltaic effect in ferroelectric and pyroelectric materials as well as the design and fabrication of advanced solar cells and other electronic and optoelectronic devices.

\section{Introduction}

Solar energy represents the most abundant and yet one of the least harvested sources of renewable energy. ${ }^{\mathbf{1}}$ Photovoltaic solar cells are the most common form of light to electrical power converters. Since the discovery of silicon-based solar cells, ${ }^{2}$ a few types of solar cell, such as semiconductor cells with $\mathrm{p}-\mathrm{n}$ junctions, ${ }^{3-8}$ polymer-inorganic hybrid cells ${ }^{9-13}$ and dyesensitized solar cells ${ }^{\mathbf{1 4 - 2 0}}$ have been developed. Recently, solar cells based on coaxial silicon nanowires with $\mathrm{p}-\mathrm{n}$ and $\mathrm{p}-\mathrm{i}-\mathrm{n}$ radial heterostructures have been fabricated..$^{3-5}$ Nanoparticles, nanorods and nanowires have been used to improve charge collection efficiency in polymer-blend ${ }^{\mathbf{1 1}}$ and dye-sensitized solar

${ }^{a}$ Shaanxi Key Laboratory for Advanced Energy Devices, Shaanxi Engineering Laboratory for Advanced Energy Technology, Key Laboratory of Macromolecular Science of Shaanxi Province, School of Materials Science and Engineering, Shaanxi Normal University, Xi'an, 710119, China. E-mail: hqyang@snnu.edu.cn; Fax: +8629-81530702

${ }^{b}$ Key Laboratory of Macromolecular Science of Shaanxi Province, School of Chemistry and Chemical Engineering, Shaanxi Normal University, Xi'an, 710119, China

${ }^{c}$ Key Laboratory of Applied Surface and Colloid Chemistry, National Ministry of Education, Shaanxi Key Laboratory for Advanced Energy Devices, Shaanxi Engineering Lab for Advanced Energy Technology, School of Materials Science and Engineering, Shaanxi Normal University, Xi'an 710119, China

$\dagger$ Electronic supplementary information (ESI) available. See DOI: 10.1039/c6ra26984b

\$ These authors contributed equally to this work. cells, ${ }^{15,20}$ to demonstrate carrier multiplication, ${ }^{21}$ and to enable low-temperature processing of photovoltaic devices. ${ }^{20,22}$ However, the charge separation principle of photogenerated
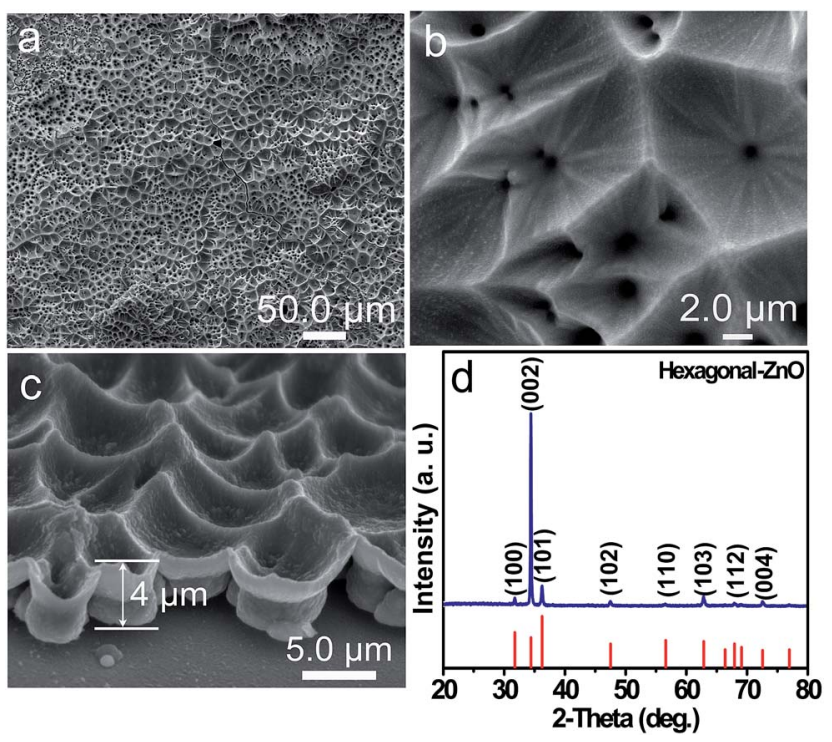

Fig. 1 (a-c) SEM images and (d) XRD pattern of the as-synthesized $\mathrm{ZnO}$ thin film. The stick pattern is the standard XRD pattern of wurtzite $\mathrm{ZnO}$ powders with $\mathrm{Cu} \mathrm{K}_{\alpha 1}$ radiation (Joint Committee on Powder Diffraction Standards Card no. 36-1451). 

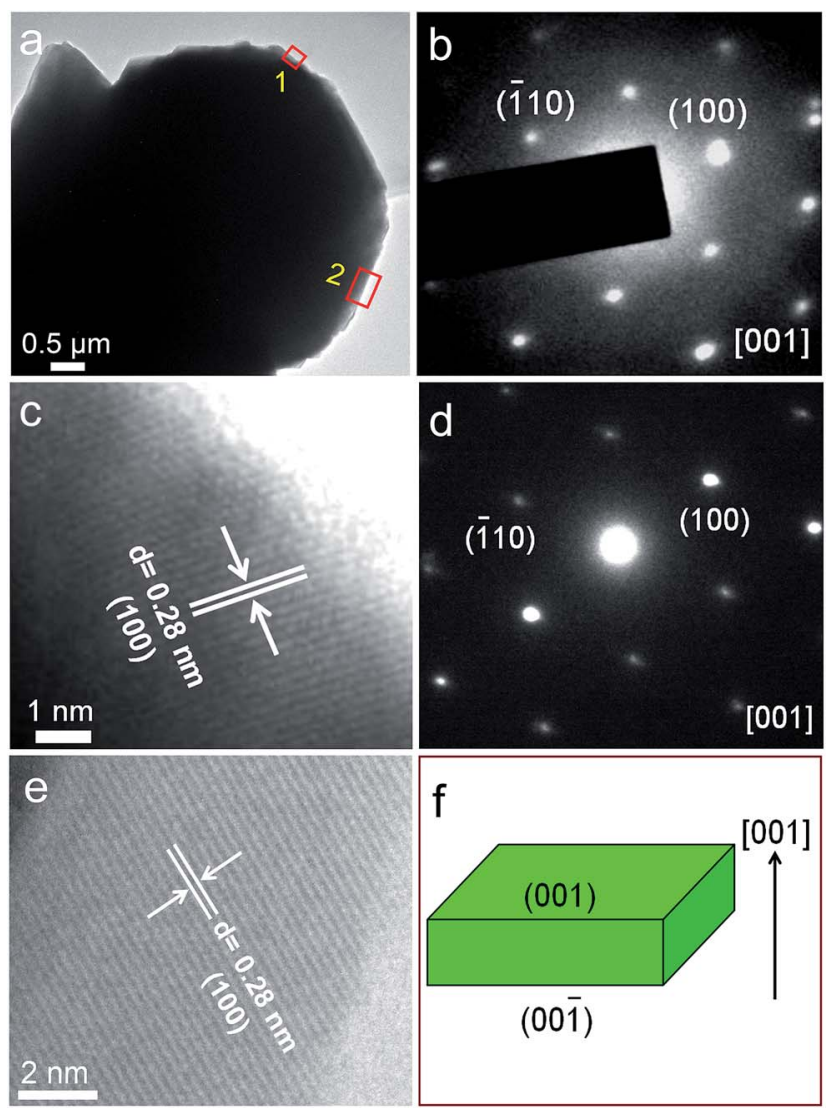

$(00 \overline{1})$

Fig. 2 (a) A representative TEM image of the $\mathrm{ZnO}$ thin film with a size of about $6.0 \mu \mathrm{m}$. ( $b$ and $c$ ) and ( $d$ and e) SAED pattern and HRTEM image from the box 1 and 2 in (a), respectively. (f) The schematic illustration of crystal orientation of the $\mathrm{ZnO}$ thin film.
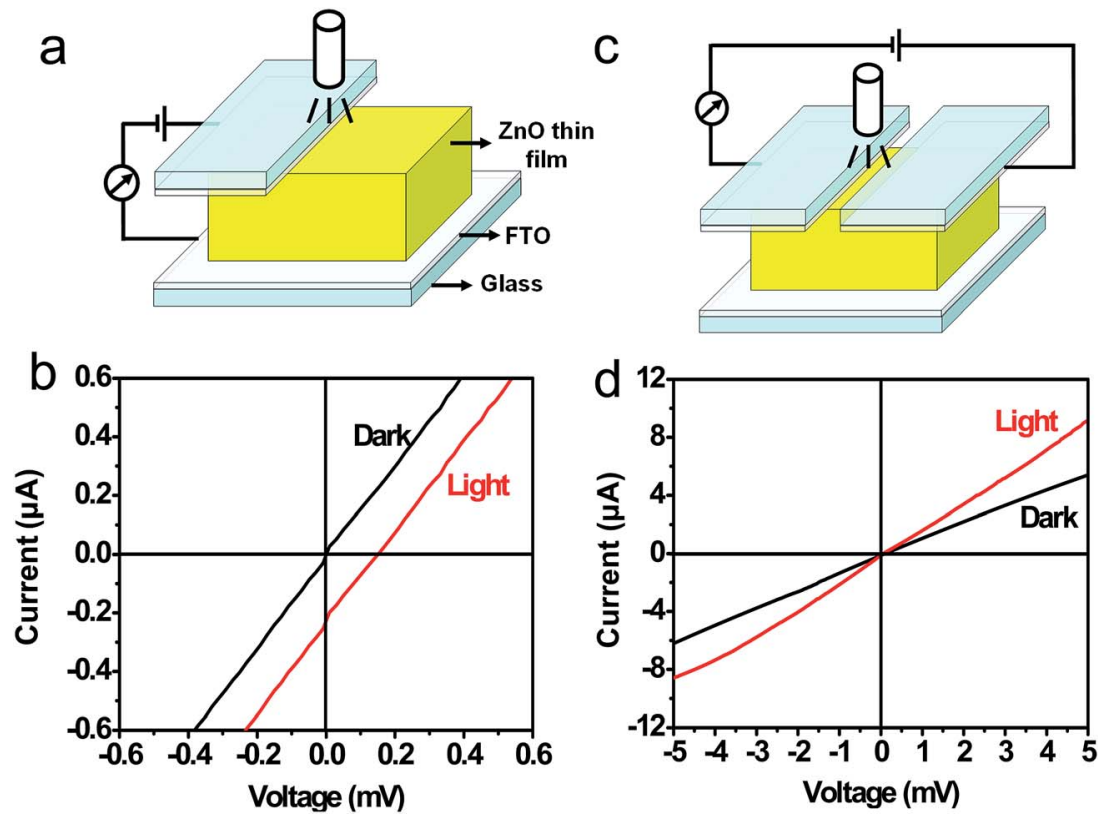

Fig. 3 ( $a$ and c) Schematic diagram of the current sensing measurement. (b and d) Current-voltage (I-V) data obtained from (a) and (c), respectively, under a $365 \mathrm{~nm}$ UV lamp (3 W) illumination. 
aqueous solution was obtained by dissolving $0.2975 \mathrm{~g}$ of $\mathrm{Zn}\left(\mathrm{NO}_{3}\right)_{2} \cdot 6 \mathrm{H}_{2} \mathrm{O}$ in $2.0 \mathrm{~mL}$ de-ionized water $\left(2.0 \times 1.2 \mathrm{~cm}^{2}\right)$. The [001] orientated $\mathrm{ZnO}$ thin film was prepared by heating $\mathrm{Zn}\left(\mathrm{NO}_{3}\right)_{2}$ solution. In a typical procedure, one of $0.5 \mathrm{M} \mathrm{Zn}\left(\mathrm{NO}_{3}\right)_{2}$ aqueous solution was added on a fluorine-doped tin oxide (FTO) glass substrate. The FTO glass substrate was placed in a quartz boat. The quartz boat was placed at center of a tubular electric furnace at $450{ }^{\circ} \mathrm{C}$. After $10 \mathrm{~min}$, the boat was taken out and cooled to room temperature. A white thin film was grown on the FTO substrate.

\subsection{Characterization}

The as-prepared thin films were characterized using X-ray diffraction (XRD), scanning electron microscopy (SEM) and transmission electron microscopy (TEM). The XRD patterns was recorded with a Haoyuan DX-2700 X-ray diffractometer operating with $\mathrm{Cu} \mathrm{K} \alpha 1$ radiation $(\lambda=1.54 \AA)$. SEM observations were carried out with a FEI Quanta 200 scanning electron microscope at an accelerating voltage of $25 \mathrm{kV}$. TEM and electron diffraction images were obtained on a JEOL JEM-3010 TEM at an accelerating voltage of $300 \mathrm{kV}$. Electrical properties of $\mathrm{ZnO}$ thin films with (001) preferred orientation were recorded by a Keithley 2601 source measurement unit at room temperature.

\section{Results and discussion}

\subsection{Synthesis and characterization of the $\mathrm{ZnO}$ thin film}

The ZnO thin film with (001) preferred orientation was fabricated by heating $\mathrm{Zn}\left(\mathrm{NO}_{3}\right)_{2}$ solutions on a FTO glass substrate at $450{ }^{\circ} \mathrm{C}$. The SEM images in Fig. 1a-c reveal that surface of the thin film is very rough, there is a large quantity of pits with the sizes of 4.0 to $9.5 \mu \mathrm{m}$ on the surface. Thickness and area of the film is about $4.0 \mu \mathrm{m}$, and $0.6 \mathrm{~cm}^{2}$, respectively. The XRD measurements (Fig. 1d) show that the as-synthesized rough thin film is wurtzite $\mathrm{ZnO}$ with a hexagonal structure. The (002) diffraction peak is overwhelming, and other peaks are very weak, revealing a strong [001] preferred orientation. The texture coefficient of (002) plane was calculated from the following equation: ${ }^{44}$

$$
\mathrm{TC}(002)=\frac{I(002)}{I_{0}(002)}\left\{\frac{1}{n} \sum \frac{I(h k l)}{I_{0}(h k l)}\right\}^{-1}
$$

where $I(h k l)$ are measured intensities of $(h k l)$ reflection, $I_{0}(h k l)$ are powder diffraction intensities of wurtzite $\mathrm{ZnO}$ according to the Joint Committee on Powder Diffraction Standards card no. $36-1451$, and $n$ is the number of diffraction peaks used in the calculations. For powders with random crystallographic orientations, the texture coefficient is 1 . The TC of (002) for the asobtained $\mathrm{ZnO}$ film is 4.07 , indicating that the film is enclosed by (001) top and (001) bottom surfaces. Fig. 2a presents a representative TEM image of the $\mathrm{ZnO}$ film with a size of about $5.8 \mu \mathrm{m}$. Fig. 2b-e show selected area electron diffraction (SAED) patterns and high-resolution TEM (HRTEM) images from the box 1 and 2 in 2a, respectively. The SAED patterns shown in Fig. $2 \mathrm{~b}$ and $\mathrm{d}$ can be indexed to [001] zone axis of singlecrystalline $\mathrm{ZnO}$ with the hexagonal structure, respectively. The lattice spacing of $0.28 \mathrm{~nm}$ between adjacent lattice planes (Fig. 2c and e) corresponds to the distance between two (100) facets. The SAED and HRTEM results further confirm that the $\mathrm{ZnO}$ film is single crystalline and enclosed by $\pm(001)$ top and bottom surfaces. The schematic illustration of crystal orientation of the $\mathrm{ZnO}$ thin film is shown in Fig. $2 \mathrm{f}$.

\subsection{Photovoltaic device based on the $\mathrm{ZnO}$ thin film}

A photovoltaic device was constructed using the [001] orientated ZnO thin film, and its schematic diagram is shown in Fig. 3a. The contact between the FTO glass electrode and the top surface of $\mathrm{ZnO}$ thin film is achieved by using a clamp. The photovoltaic properties of the $\mathrm{ZnO}$ thin film were characterized under a $365 \mathrm{~nm}$ ultraviolet (UV) lamp ( $3 \mathrm{~W}$ ) illumination. The illumination area is about $2 \mathrm{~cm}^{2}$, and the distance between the lamp and $\mathrm{ZnO}$ thin film is approximately $2 \mathrm{~cm}$. Current-voltage $(I-V)$ curves measured at a bias of $0.6 \mathrm{mV}$ are shown in Fig. $3 \mathrm{~b}$. The $I-$ $V$ data recorded from the device yields an open-circuit voltage
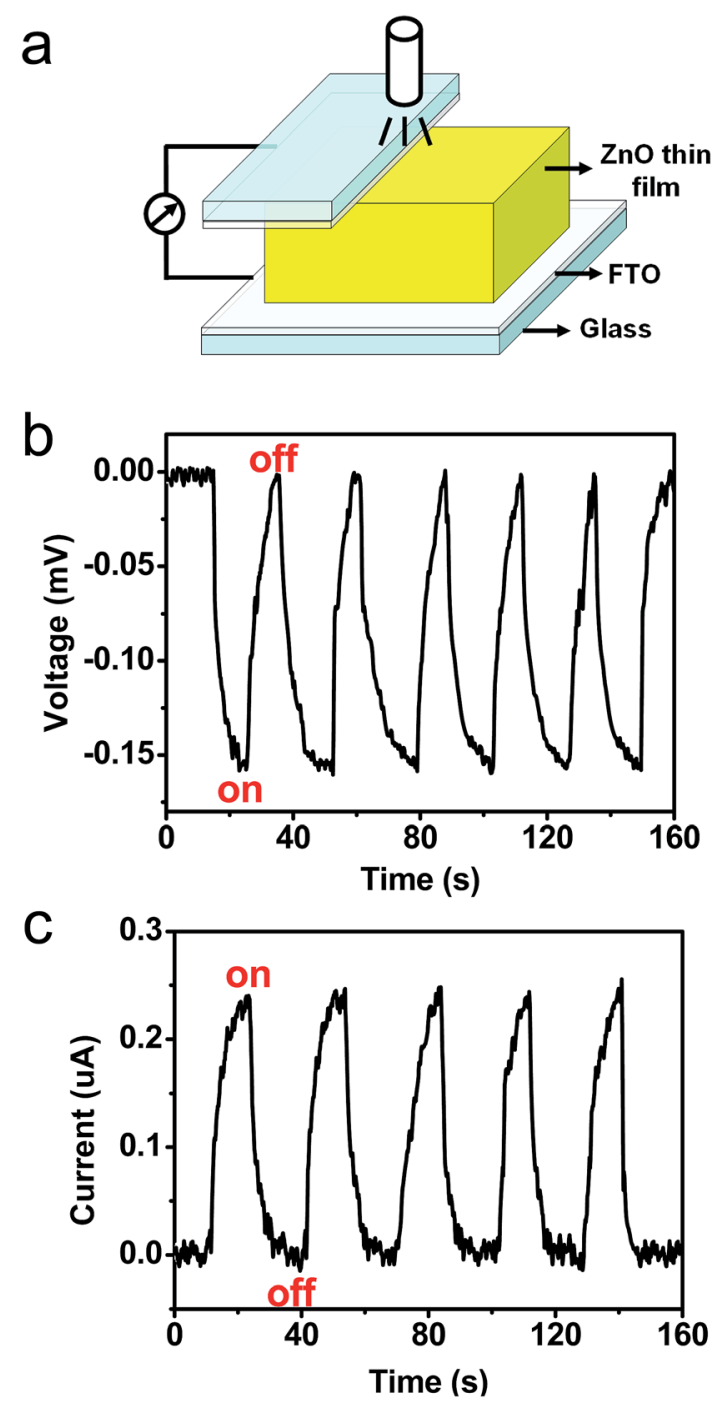

Fig. 4 (a) Schematic diagram of the solar cell. ( $b$ and c) The measured $V_{\text {oc }}$ and $I_{\text {sc }}$ when the UV lamp was turned on and off. 
$\left(V_{\mathrm{oc}}\right)$ of about $0.16 \mathrm{mV}$, a short-circuit current $\left(I_{\mathrm{sc}}\right)$ of $0.25 \mu \mathrm{A}$. The value of fill factor is $20.0 \%$. The results reveal that a photovoltaic device can be constructed using an [001]
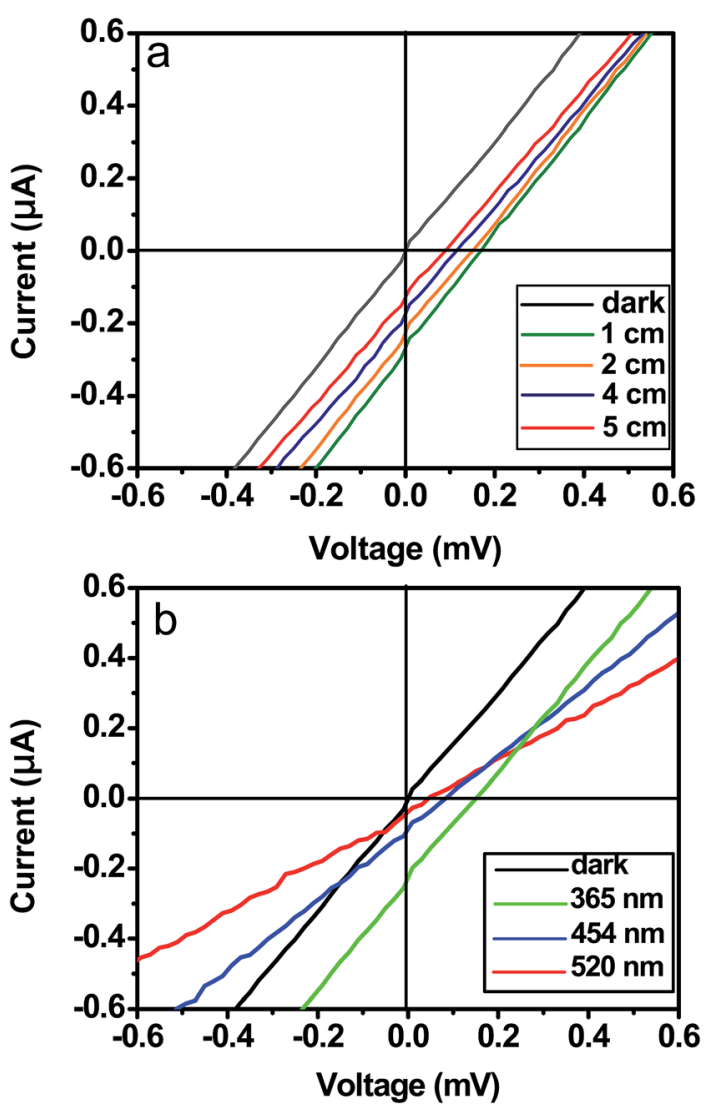

Fig. 5 (a) $I-V$ curves measured under illumination of the UV lamp at the distances of 1.0 to $5.0 \mathrm{~cm}$. (b) $I-V$ curves of the $\mathrm{ZnO}$ thin film were measured under a $450 \mathrm{~nm}$ blue light or $520 \mathrm{~nm}$ green light lamp illumination. orientated wurtzite $\mathrm{ZnO}$ thin film. In the photovoltaic device, when the both FTO electrodes are all located on the top (001) surface of the $\mathrm{ZnO}$ thin film (Fig. 3c), the as-obtained dark and light $I-V$ curves are presented in Fig. $3 \mathrm{~d}$. We notice that the UVexposed $\mathrm{ZnO}$ thin film merely has a lower resistivity, and does not exhibit a photovoltaic property. The results reveal that the photovoltaic property rests with the orientation of the $\mathrm{ZnO}$ thin film. None but when the two electrodes are attached to top and bottom surfaces of the $\mathrm{ZnO}$ thin film, respectively, the $\mathrm{ZnO}$ thin film shows photovoltaic behavior. Moreover, when the UV lamp was turned on and off, the $V_{\mathrm{oc}}$ and $I_{\mathrm{sc}}$ were measured without power supply. The schematic diagram of the current-sensing measurement is shown in Fig. 4a. Fig. $4 \mathrm{~b}$ and c plots the $V_{\mathrm{oc}}$ and $I_{\mathrm{sc}}$ as a function of time as the UV-lamp was switched on and off, respectively. It is evident that the $V_{\mathrm{oc}}$ and $I_{\mathrm{sc}}$ can be reversibly changed between 0 and $0.16 \mathrm{mV}$ and between 0 and $0.25 \mu \mathrm{A}$, respectively. $I-V$ measurements were studied under the different UV light intensities, and the different UV light intensities are achieved by changing the distance between the lamp and $\mathrm{ZnO}$ thin film. Fig. 5a shows $I-V$ curves measured under illumination of the UV lamp at the distances of 1.0 to $5.0 \mathrm{~cm}$. Obviously, UV light intensity reduced with an increase on the distance between the lamp and $\mathrm{ZnO}$ film, and thus $V_{\mathrm{oc}}$ and $I_{\mathrm{sc}}$ decreased. In addition, the $I-V$ curves of the $\mathrm{ZnO}$ thin film were measured under a $450 \mathrm{~nm}$ blue light or $520 \mathrm{~nm}$ green light lamp illumination, and the results are shown in Fig. $5 \mathrm{~b}$. It was found that values of the $V_{\mathrm{oc}}$ and $I_{\mathrm{sc}}$ obtained under illumination of both the blue light and green light lamps are distinctly lower than that obtained under the UV lamp illumination. ZnO has a band gap $3.37 \mathrm{eV}$, (corresponding to wavelength $368 \mathrm{~nm}$ ), the UV light can induce excitation of electrons from the top of the valence band to the bottom of the conductor band, but $450 \mathrm{~nm}$ blue light and $520 \mathrm{~nm}$ green light can not, the UV lamp is thus used. The results further indicate that the photon-to-electron conversion can be achieved by the [001] orientated $\mathrm{ZnO}$ thin film. a
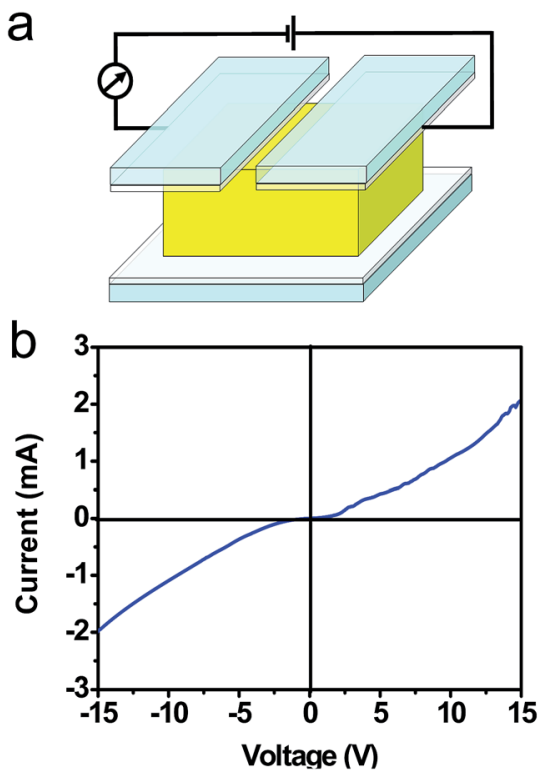

C
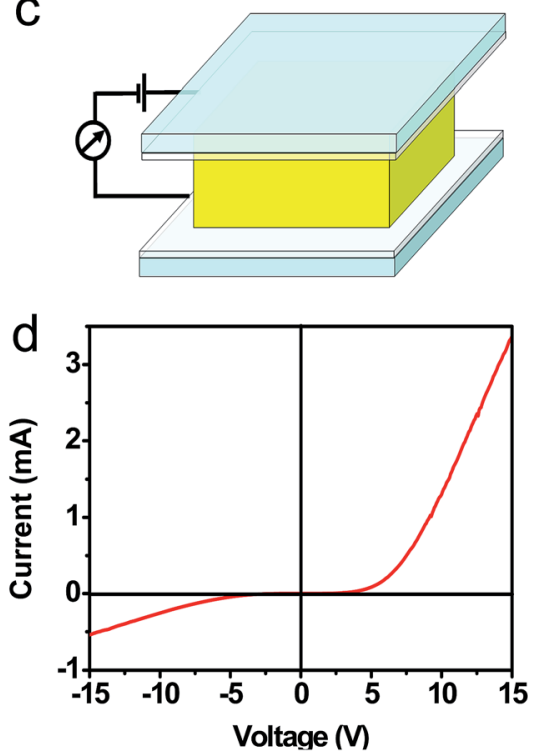

Fig. 6 (a and b) Schematic diagram of the current sensing measurement. (c and d) $I-V$ curves obtained from (a) and (c), respectively. 

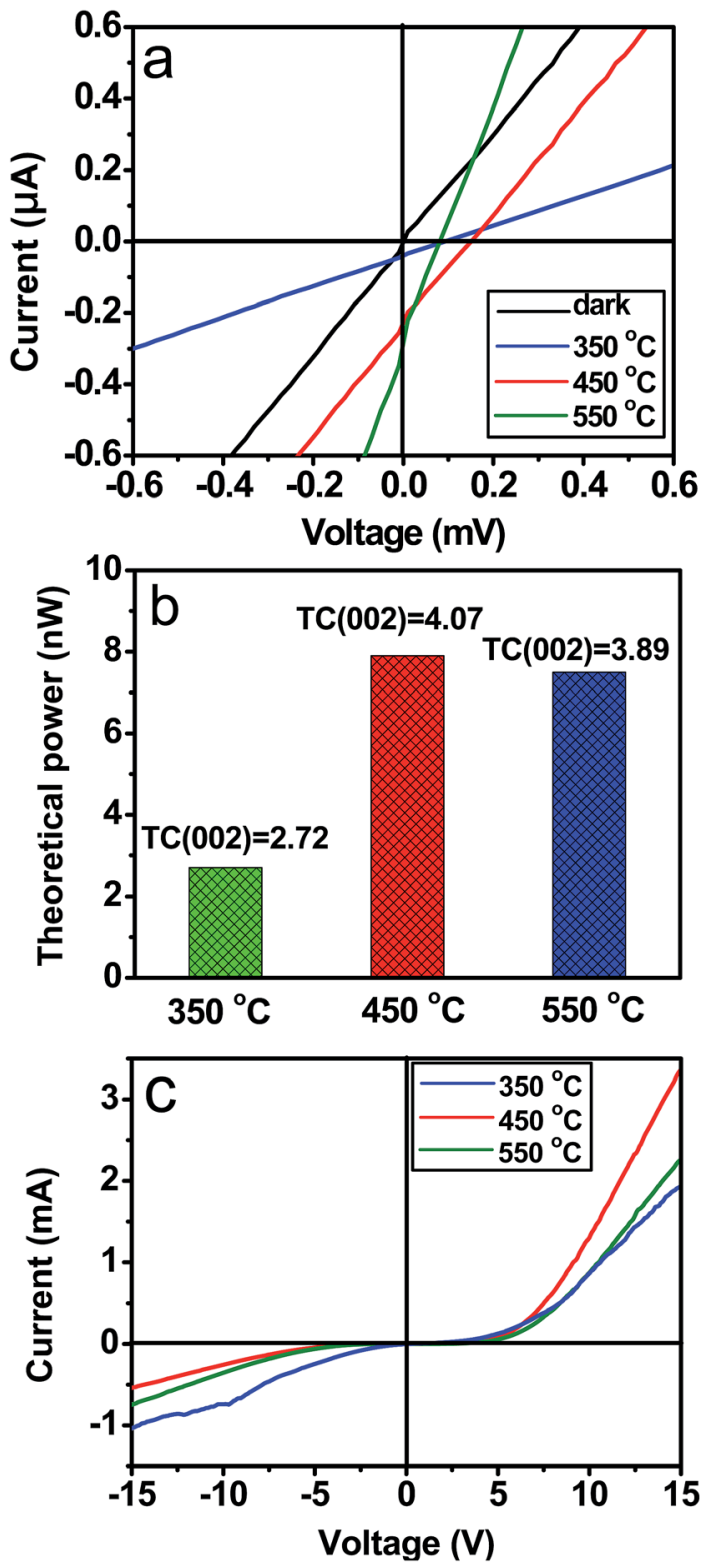

Fig. 7 ( $\mathrm{a}$ and b) Photovoltaic properties of the $\mathrm{ZnO}$ thin films with various texture coefficients of (002) obtained at different temperatures under the UV lamp illumination. (c) Dark I-V curves of this three kinds of $\mathrm{ZnO}$ thin films along [001] direction.

\subsection{An internal electric field within the $\mathrm{ZnO}$ thin film}

Electrical transport through the [001] orientated $\mathrm{ZnO}$ thin film was investigated in dark, the dark $I-V$ curves measured at a bias of $15 \mathrm{~V}$ are shown in Fig. 6a-d. When the both FTO electrodes are all located on the top (001) surface of the $\mathrm{ZnO}$ thin film (Fig. 6a), the as-obtained $I-V$ curve exhibit nonlinear behavior (Fig. 6b) and under a negative applied bias were symmetrically repeated under a positive applied bias, which is similar to those observed in nanocontacts between $\left(\mathrm{La}_{0.7} \mathrm{Sr}_{0.3}\right) \mathrm{MnO}_{3}$ crystals ${ }^{45}$ and between $\mathrm{Au}$ wires. ${ }^{46}$ The FTO-ZnO(001)-FTO contacts are not Schottky junction because that Schottky junction is a contact between a metal and a semiconductor that has rectifying properties. $^{47}$ According to ref. 45, 46 and 48, the symmetrical nonlinear $I-V$ curve is typical for tunneling barrier formation in FTO-ZnO(001)-FTO contacts. That is, the FTO$\mathrm{ZnO}(001)-\mathrm{FTO}$ contacts are defective ohmic contacts. However, when the FTO electrode is located on the top (001) and bottom (001) surfaces of the ZnO thin film, respectively (Fig. 6c), the asobtained $I-V$ curve exhibits a diode-like property (Fig. $6 \mathrm{~d}$ ), that is, little current flows in reverse bias, whereas there is a sharp current onset in forward bias. This diode-like behavior is similar to the $\mathrm{p}-\mathrm{n}$ junction diodes, ${ }^{49}$ the basis for many critical electronic and optoelectronic devices. In a standard $\mathrm{p}-\mathrm{n}$ junction, rectification arises from the potential barrier formed at the interface between p- and n-type materials. ${ }^{48}$ The results indicate that the $I-V$ characteristic of the $\mathrm{ZnO}$ thin film depends on its orientation. None but as the two electrodes are attached to top and bottom surfaces of the $\mathrm{ZnO}$ thin film, respectively, the $\mathrm{ZnO}$ thin film shows rectification property.

$\mathrm{ZnO}$ thin films with various texture coefficients of (002) can be obtained by changing the reaction temperature. SEM images and XRD patterns of the $\mathrm{ZnO}$ thin films synthesized by heating $\mathrm{Zn}\left(\mathrm{NO}_{3}\right)_{2}$ solutions at 350 and $550{ }^{\circ} \mathrm{C}$ for $10 \mathrm{~min}$ on the FTO glass substrates are shown in Fig. $\mathrm{S} 1$ and $\mathrm{S} 2, \dagger$ respectively. The SEM and XRD observations reveal that the products obtained at 350 and $550{ }^{\circ} \mathrm{C}$ are also the wurtzite $\mathrm{ZnO}$ thin films with very rough surfaces, and their thickness is about $4.0 \mu \mathrm{m}$. Area of the both $\mathrm{ZnO}$ thin films is about $0.6 \mathrm{~cm}^{2}$. Moreover, it is found that the both $\mathrm{ZnO}$ thin films show lower intensity ratios of (001) to other diffraction peaks in comparison with those from XRD pattern of the $\mathrm{ZnO}$ thin films obtained at $450{ }^{\circ} \mathrm{C}$ (Fig. 1d). Texture coefficients of (002) of the as-obtained $\mathrm{ZnO}$ films at 350 and $550{ }^{\circ} \mathrm{C}$ are 2.72 and 3.89 , respectively, they are lower than 4.07 of the $\mathrm{ZnO}$ thin films obtained at $450{ }^{\circ} \mathrm{C}$.

The photovoltaic properties of the as-obtained $\mathrm{ZnO}$ films at 350 and $550{ }^{\circ} \mathrm{C}$ are characterized under the $365 \mathrm{~nm}$ ultraviolet lamp illumination, the results are shown in Fig. 7a. Apparently, the photovoltaic effect is also observed in the both $\mathrm{ZnO}$ films. Under UV light irradiation, $V_{\mathrm{oc}}$ of the $\mathrm{ZnO}$ films obtained at 350 and $550{ }^{\circ} \mathrm{C}$ is 0.10 and $0.08 \mathrm{mV}$, respectively, and their $I_{\mathrm{sc}}$ is 0.05 and $0.32 \mu \mathrm{A}$, respectively. The TC(002), $V_{\mathrm{oc}}, I_{\mathrm{sc}}$ and theoretical power of the $\mathrm{ZnO}$ films obtained at different reaction

Table 1 The $\mathrm{TC}(002)$ and the $V_{\mathrm{oc}}, I_{\mathrm{sc}}$ and theoretical power of the $\mathrm{ZnO}$ films obtained at different reaction temperatures

\begin{tabular}{lllllr}
\hline Sample No. & Temperature $\left({ }^{\circ} \mathrm{C}\right)$ & Time $(\mathrm{min})$ & $\mathrm{TC}(002)$ & $V_{\text {oc }}(\mathrm{mV})$ & $\begin{array}{l}\text { Theoretical } \\
\text { power }(\mathrm{nW})\end{array}$ \\
\hline I & 350 & 10 & 2.72 & 0.10 & 0.05 \\
II & 450 & 10 & 4.07 & 0.16 & 0.005 \\
III & 550 & 10 & 3.89 & 0.08 & 0.040
\end{tabular}


temperatures are summarized in Table 1 and Fig. 7b. To all appearances, $V_{\text {oc }}$ and theoretical power of the $\mathrm{ZnO}$ thin film devices increase with the $\mathrm{TC}(002)$, and thus the photovoltaic properties can be improved by increasing the $\mathrm{TC}(002)$. In addition, the dark $I-V$ curves of the $\mathrm{ZnO}$ films obtained at 350 and $550{ }^{\circ} \mathrm{C}$ were measured at a bias of $15 \mathrm{~V}$, and the results are shown in Fig. 7c. It was found that when the $\mathrm{TC}(002)$ of the $\mathrm{ZnO}$ films decreases the forward current reduces and reverse current increases. That is, the rectifying properties of the $\mathrm{ZnO}$ films depend on the TC(002).

In addition, XRD, photovoltaic property and dark $I-V$ curves of an [001] orientated single-crystalline $\mathrm{ZnO}$ wafer with a thickness of $0.5 \mathrm{~mm}$ and a size of $1.0 \times 1.0 \mathrm{~cm}^{2}$ were measured, and the results are shown in Fig. S3. $\dagger$ Fig. S3a $\uparrow$ shows XRD pattern of the single-crystalline ZnO wafer. Only the (002) and (004) peaks were observed in the XRD pattern, which confirms that the single-crystalline $\mathrm{ZnO}$ wafer is enclosed by $\pm(001)$ top and bottom surfaces. The schematic illustration of crystal orientation of the single-crystalline $\mathrm{ZnO}$ wafer is shown in inset of Fig. S3a. $\dagger$ Fig. S3b and $\mathrm{c} \dagger$ shows the photovoltaic property and dark $I-V$ curve of the [001] orientated single-crystalline $\mathrm{ZnO}$ wafer, respectively. The $V_{\mathrm{oc}}$ and $I_{\mathrm{sc}}$ of the single-crystalline $\mathrm{ZnO}$ wafer are $0.27 \mathrm{mV}$ and $1.08 \mu \mathrm{A}$, respectively. $I-V$ curve in Fig. S3c $\dagger$ displays diode-like properties. The results indicate that the [001] orientated single-crystalline ZnO also exhibits photovoltaic and rectifying properties.

Moreover, the $\mathrm{ZnO}$ thin films with a range of (002) texture coefficients also can be synthesized by heating $\mathrm{Zn}\left(\mathrm{NO}_{3}\right)_{2}$ solutions at 350,450 and $550{ }^{\circ} \mathrm{C}$ on a indium-doped tin oxide (ITO) coated glass substrate. XRD observations (Fig. 8a) reveal that $\mathrm{TC}(002)$ of the products can be changed by adjusting the heating temperature, $\mathrm{TC}(002)$ value of the as-obtained $\mathrm{ZnO}$ films at 350,450 and $550{ }^{\circ} \mathrm{C}$ is $2.88,4.16$ and 3.90 , respectively. Photovoltaic property and dark $I-V$ curves of the $\mathrm{ZnO}$ thin films with different TC(002) were measured, and the results are shown in Fig. $8 \mathrm{~b}$ and Table 2. Apparently, the $V_{\mathrm{oc}}, I_{\mathrm{sc}}$ and theoretical power of the $\mathrm{ZnO}$ thin film devices increase with an increase on the $\mathrm{TC}(002)$, and the rectifying property was improved (Fig. 8c). On the basis of the investigations described above, we conclude that the rectification and photovoltaic properties are caused by the $\mathrm{ZnO}$ thin film with [001] preferred orientation instead of the $\mathrm{ZnO} / \mathrm{FTO}$ interfaces. There is an internal electric field in the [001] orientated $\mathrm{ZnO}$ thin film.

\subsection{Physical mechanism of photovoltaic effect}

According to ref. 43, the structure and atomic charge of wurtzite $\mathrm{ZnO}$ in [001] direction is shown in Fig. 9a, each layer contains all

Table 2 The TC(002) and the $V_{\text {oc }} I_{\text {sc }}$ and theoretical power of the $\mathrm{ZnO}$ films obtained at different reaction temperatures on the ITO glass substrates for $10 \mathrm{~min}$

\begin{tabular}{llllll}
\hline $\begin{array}{l}\text { Sample } \\
\text { No. }\end{array}$ & $\begin{array}{l}\text { Temperature } \\
\left({ }^{\circ} \mathrm{C}\right)\end{array}$ & $\mathrm{TC}(002)$ & $V_{\mathrm{oc}}(\mathrm{mV})$ & $I_{\mathrm{sc}}(\mu \mathrm{A})$ & $\begin{array}{l}\text { Theoretical } \\
\text { power }(\mathrm{nW})\end{array}$ \\
\hline i & 350 & 2.88 & 0.12 & 2.35 & 0.28 \\
ii & 450 & 4.16 & 0.88 & 4.15 & 3.65 \\
iii & 550 & 3.90 & 0.56 & 3.36 & 1.88
\end{tabular}
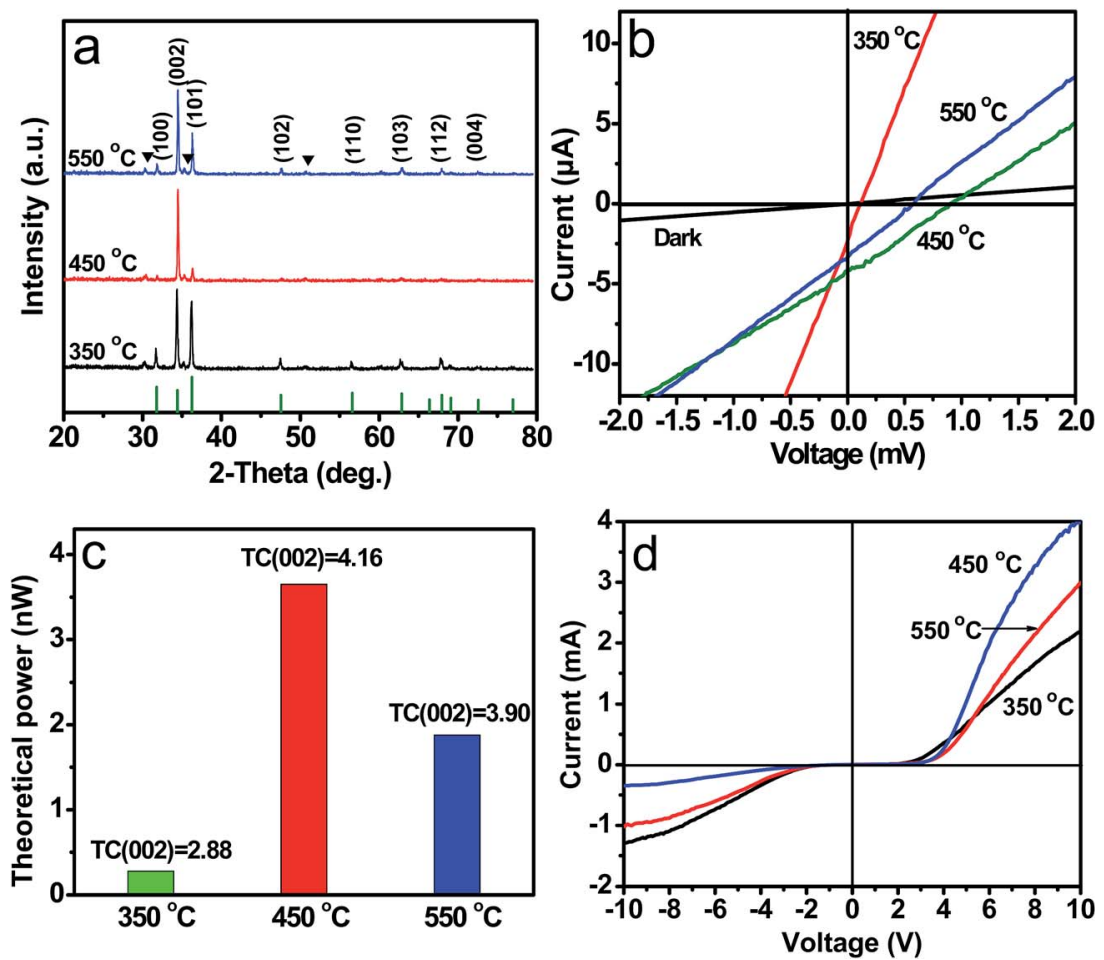

Fig. 8 (a) XRD patterns of $\mathrm{ZnO}$ thin films synthesized by heating $\mathrm{Zn}\left(\mathrm{NO}_{3}\right)_{2}$ solutions on the ITO glass substrates. (b and c) Photovoltaic properties and (d) dark $I-V$ curves of the $\mathrm{ZnO}$ thin films with different texture coefficients of (002) on the ITO glass substrates. 
a

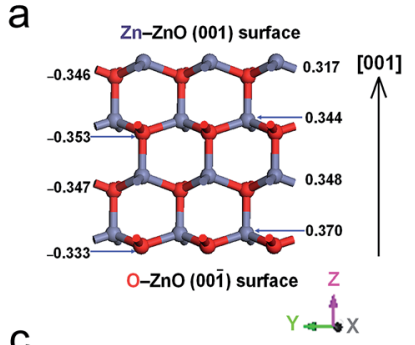

$\mathrm{b}$

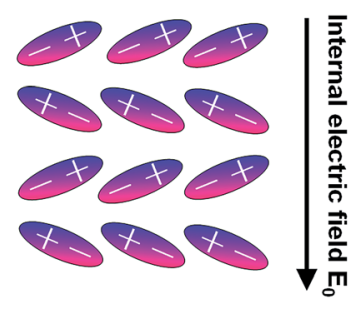

C

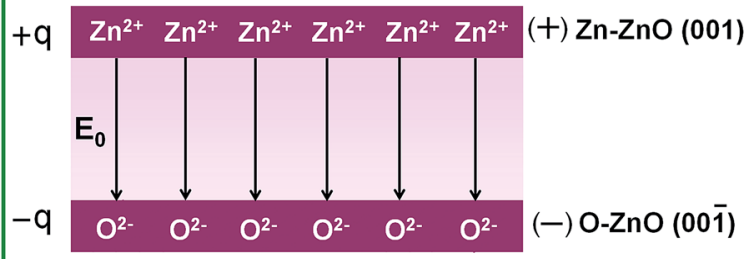

d
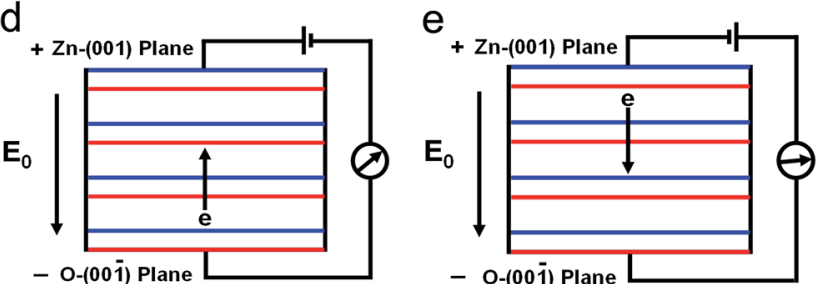

Fig. 9 (a) The structure and atomic charge of wurtzite $\mathrm{ZnO}$ in [001] direction. Copyright 2015, Elsevier. (b) The positive and negative charge distribution in [001] direction. (c) Schematic diagram of the parallel-plate capacitor constructed with a positive $\mathrm{Zn}-\mathrm{ZnO}$ (001) plate and a negative $\mathrm{O}-\mathrm{ZnO}(00 \overline{1})$ plate. Schematic diagram of (d) the forward-biased and (e) reverse biased [001] orientated $\mathrm{ZnO}$ thin film.

positive $\mathrm{Zn}^{2+}$ ions or all negative $\mathrm{O}^{2-}$ ions in the [001] direction, the positive and negative charge distribution is shown in Fig. 9b. The charge center of the cation and anion separates and result in an electric dipole. The electric dipole can create an electric field. An internal electric field $E_{0}$ is therefore generated from the positive $\mathrm{Zn}-\mathrm{ZnO}(001)$ to negative $\mathrm{O}-\mathrm{ZnO}(00 \overline{1})$ planes due to the spontaneous polarization. In other word, the polar structure can be considered to a parallel-plate capacitor constructed with a positive $\mathrm{Zn}-\mathrm{ZnO}$ (001) plate and a negative O$\mathrm{ZnO}(00 \overline{1})$ plate, as shown in Fig. 9c. There is an uniform internal electric field $E_{0}$ between $\mathrm{Zn}-\mathrm{ZnO}(001)$ and O-ZnO (001) plates, and its magnitude is defined as follows:

$$
E_{0}=\frac{q}{\varepsilon_{\mathrm{r}} \varepsilon_{0} S}
$$

where $q$ is electric change on $\mathrm{Zn}-\mathrm{ZnO}(001)$ or $\mathrm{O}-\mathrm{ZnO}(00 \overline{1})$ plate, $S$ is area of the plate, $\varepsilon_{\mathrm{r}}$ and $\varepsilon_{0}$ are relative permittivity of $\mathrm{ZnO}$ in [001] direction and the vacuum permittivity, respectively.

When a battery is connected across the $\mathrm{ZnO}$ thin film, the asobtained dark $I-V$ curve at a bias of $15 \mathrm{~V}$ exhibits a diode-like property. Under forward bias conditions, the positive terminal of the battery is attached to the positive $\mathrm{Zn}-\mathrm{ZnO}(001)$ plane and the negative terminal to the negative $\mathrm{O}-\mathrm{ZnO}(00 \overline{1})$ plane, as shown in Fig. 9d. The applied bias $V$ is in the same direction to the internal electric field $E_{0}$. The voltage $V$ across the $\mathrm{ZnO}$ thin film increases. The higher voltage drive electrons and holes migrate to positive $\mathrm{Zn}-\mathrm{ZnO}$ (001) planes and negative $\mathrm{O}-\mathrm{ZnO}$ (001) planes, respectively, thus, there is a sharp current onset in forward bias. Under reverse bias conditions, the positive $\mathrm{Zn}-$ $\mathrm{ZnO}$ (001) plane is connected to the negative terminal and the negative $\mathrm{O}-\mathrm{ZnO}(00 \overline{1})$ plane to the positive terminal, as depicted schematically in Fig. 9e. The applied bias is in the opposite direction to internal electric field $E_{0}$, the flow of electrons and holes is prevented by the internal electric field $E_{0}$ in the $\mathrm{ZnO}$ thin film, there therefore is a very small reverse current.

The presence of the internal electric field $E_{0}$ from the $\mathrm{Zn}-$ $\mathrm{ZnO}(001)$ to O-ZnO (001) plane is the fundamental physical basis of the ZnO thin film photovoltaic device. When the [001] orientated $\mathrm{ZnO}$ thin films was irradiated by a $365 \mathrm{~nm}$ UV lamp. The electrons from the top of the valence band are excited to the bottom of the conductor band, generating electron-hole pairs in the $\mathrm{ZnO}$ thin film (Fig. 10a). The photogenerated electrons and holes migrate to positive polar $\mathrm{Zn}-$ ZnO (001) and negative polar O-ZnO (001) planes, respectively, under the internal electric field $E_{0}$ (Fig. 10b). When these electrons and holes were collected by the top and bottom electrodes connected to an external load, the photon energy is converted into electricity. Photoinduced electrons and holes were separated under the internal electric field $E_{0}$, creating a photovoltage, the photovoltage is in the opposite direction to internal electric field $E_{0}$. The spontaneous polarization take place in the [001] direction of wurtzite $\mathrm{ZnO}$, and thus the electric dipole and the internal electric field $E_{0}$ increase in the $\mathrm{ZnO}$ thin film with the $\mathrm{TC}(002)$. The rectification and photovoltaic properties are therefore improved by increasing the $\mathrm{TC}(002)$.
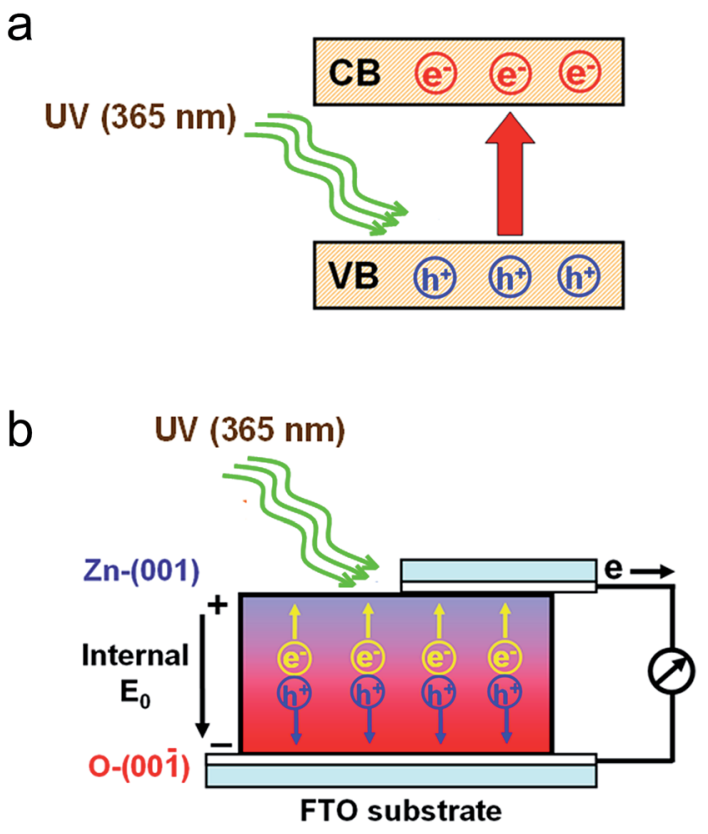

Fig. 10 (a) Generation of the photogenerated electrons and holes. (b) Flow of the photogenerated charges driven by the internal electric field. 


\section{Conclusions}

An [001] orientated wurtzite $\mathrm{ZnO}$ photovoltaic device without $\mathrm{p}-$ $\mathrm{n}$ junction was obtained in this work. The principle of the photovoltaic effect is distinct from that of semiconductor cells with $\mathrm{p}-\mathrm{n}$ junction. Based on the polar structure of $\mathrm{ZnO}\{001\}$ facets, a new physical mechanism of photo-to-electron conversion was proposed. An internal electric field is generated from the positive $\mathrm{Zn}-\mathrm{ZnO}(001)$ to negative $\mathrm{O}-\mathrm{ZnO}$ (001) planes due to the spontaneous polarization. The electrostatic potential provides a driving force for flow of the photogenerated electrons and holes. The present study motivates us to further develop photovoltaic devices beyond $\mathrm{p}-\mathrm{n}$ junction by the thin film texturing strategy. Moreover, the photo-to-electron conversion mechanism may be applied to photovoltaic effect in ferroelectric and pyroelectric materials and provides a new insight into the design and fabrication of advanced solar cells and other electronic and optoelectronic devices.

\section{Acknowledgements}

This work was supported by the National Natural Science Foundation of China (Grant No. 21073116 and 21501116), and the Fundamental Research Funds for the Central Universities (GK 201601003).

\section{Notes and references}

1 Z. Y. Fan, H. Razavi, J. W. Do, A. Moriwaki, O. Ergen, Y. L. Chueh, P. W. Leu, J. C. Ho, T. Takahashi, L. A. Reichertz, S. Neale, K. Yu, M. Wu, J. W. Ager and A. Javey, Nat. Mater., 2009, 8, 648-653.

2 D. M. Chapin, C. S. Fuller and G. L. Pearson, J. Appl. Phys., 1954, 25, 676-677.

3 B. Tian, Z. T. J. Kempa and C. M. Lieber, Chem. Soc. Rev., 2009, 38, 16-24.

4 A. I. Hochbaum and P. D. Yang, Chem. Rev., 2010, 110, 527546.

5 B. Z. Tian, X. L. Zheng, T. J. Kempa, Y. Fang, N. F. Yu, G. H. Yu, J. L. Huang and C. M. Lieber, Nature, 2007, 449, 885-890.

6 C. Liu, Y. J. Hwang, H. E. Jeong and P. D. Yang, Nano Lett., 2011, 11, 3755-3758.

7 J. Tang, K. W. Kemp, S. Hoogland, K. S. Jeong, H. Liu, L. Levina, M. Furukawa, X. H. Wang, R. Debnath, D. Cha, K. W. Chou, A. Fischer, A. Amassian, J. B. Asbury and E. H. Sargent, Nat. Mater., 2011, 10, 765-771.

8 J. Wallentin, N. Anttu, D. Asoli, M. Huffman, I. Åberg, M. H. Magnusson, G. Siefer, P. Fuss-Kailuweit, F. Dimroth, B. Witzigmann, H. Q. Xu, L. Samuelson, K. Deppert and M. T. Borgström, Science, 2013, 339, 1057-1060.

9 X. J. Shen, B. Q. Sun, D. Liu and S. T. Lee, J. Am. Chem. Soc., 2011, 133, 19408-19415.

10 S. Dowland, T. Lutz, A. Ward, S. P. King, A. Sudlow, M. S. Hill, K. C. Molloy and S. A. Haque, Adv. Mater., 2011, 23, 27392744 .
11 W. U. Huynh, J. J. Dittmer and A. P. Alivisatos, Science, 2002, 295, 2425-2427.

12 J. H. Noh, S. H. Im, J. H. Heo, T. N. Mandal and S. I. Seok, Nano Lett., 2013, 13, 1764-1769.

13 N. J. Jeon, J. Lee, J. H. Noh, M. K. Nazeeruddin, M. Grätzel and S. I. Seok, J. Am. Chem. Soc., 2013, 135, 19087-19090.

14 B. O'Regan and M. Grätzel, Nature, 1991, 353, 737-740.

15 M. Law, L. Greene, J. Johnson, R. Saykally and P. D. Yang, Nat. Mater., 2005, 4, 455-459.

16 J. J. Wu, Y. R. Chen, W. P. Liao, C. T. Wu and C. Y. Chen, ACS Nano, 2010, 4, 5679-5684.

17 A. Yella, H. W. Lee, H. N. Tsao, C. Yi, A. K. Chandiran, M. K. Nazeeruddin, E. W. G. Diau and C. Y. Yeh, Science, 2011, 334, 629-634.

18 W. Q. Wu, Y. F. Xu, H. S. Rao, C. Y. Su and D. B. Kuang, J. Am. Chem. Soc., 2014, 136, 6437-6445.

19 A. Hagfeldt, G. Boschloo, L. C. Sun, L. Kloo and H. Pettersson, Chem. Rev., 2010, 110, 6595-6663.

20 J. B. Baxter and E. S. Aydil, Nanowire-Based Dye-Sensitized Solar Cells, Appl. Phys. Lett., 2005, 86, 053114.

21 A. Luque, A. Martí and A. J. Nozik, MRS Bull., 2007, 32, 236241.

22 M. Grätzel, Nature, 2001, 414, 338-344.

23 A. Zenkevich, Y. Matveyev, K. Maksimova, R. Gaynutdinov, A. Tolstikhina and V. Fridkin, Phys. Rev. B: Condens. Matter Mater. Phys., 2014, 90, 161409.

24 P. S. Brody, Solid State Commun., 1973, 12, 673-676. 25 M. Alexe and D. Hesse, Nat. Commun., 2011, 2, 1-5.

26 S. Y. Yang, J. Seidel, S. J. Byrnes, P. Shafer, C. H. Yang, M. D. Rossell, P. Yu, Y. H. Chu, J. F. Scott, J. W. Age, L. W. Martin and R. Ramesh, Nat. Nanotechnol., 2010, 5, 143-147.

27 R. Moubah, O. Rousseau, D. Colso, A. Artemenk, M. Maglion and M. Viret, Adv. Funct. Mater., 2012, 22, 4814-4818.

28 G. H. Zhang, H. Wu, G. B. Li, Q. Z. Huang, C. Y. Yang, F. Q. Huang, F. H. Liao and G. H. Lin, Sci. Rep., 2013, 3, 1265.

29 F. G. Zheng, Y. Xin, W. Huang, J. X. Zhang, X. F. Wang, M. R. Shen, W. Dong, L. Fang, Y. B. Bai, X. Q. Shen and J. H. Hao, J. Mater. Chem. A, 2014, 2, 1363-1368.

30 I. Grinberg, D. V. West, M. Torres, G. Y. Gou, D. M. Stein, L. Y. Wu, G. N. Chen, E. M. Gallo, A. R. Akbashev, P. K. Davies, J. E. Spanier and A. M. Rappe, Nature, 2013, 503, 509-512.

31 D. W. Cao, C. Y. Wang, F. G. Zheng, W. Dong, L. Fang and M. R. Shen, Nano Lett., 2012, 12, 2803-2809.

32 R. Nechache, C. Harnagea, S. Li, L. Cardenas, W. Huang, J. Chakrabartty and F. Rosei, Nat. Photonics, 2015, 9, 61-67. 33 A. Lempicki, Phys. Rev., 1959, 113, 1204-1209.

34 E. S. Jang, J. H. Won, S. J. Hwang and J. H. Choy, Adv. Mater., 2006, 18, 3309-3312.

35 X. X. Wang, M. C. Liu, Z. H. Zhou and L. J. Guo, J. Phys. Chem. $C, 2015,119,20555-20560$.

36 C. X. Li, L. J. Han, R. J. Liu, H. H. Li, S. J. Zhang and G. J. Zhang, J. Mater. Chem., 2012, 22, 23815-23820.

37 R. Jin, M. Y. Su, J. Wang, P. Zhang, M. Cui, Y. Chen and H. Q. Yang, Mater. Res. Bull., 2012, 47, 3070-3077. 
38 G. P. Han, L. Wang, C. J. Pei, R. Y. Shi, B. Liu, H. Zhao, H. Q. Yang and S. Z. Liu, J. Alloys Compd., 2014, 610, 62-68.

39 Y. Chen, L. N. Zhang, L. C. Ning, C. J. Zhang, H. Zhao, B. Liu and H. Q. Yang, Chem. Eng. J., 2015, 264, 557-564.

40 B. Liu, H. Q. Yang, A. H. Wei, H. Zhao, L. C. Ning, C. J. Zhang and S. Z. Liu, Appl. Catal., B, 2015, 172-173, 165-173.

41 B. Liu, L. Ma, L. C. Ning, C. J. Zhang, G. P. Han, C. J. Pei, H. Zhao, S. Z. Liu and H. Q. Yang, ACS Appl. Mater. Interfaces, 2015, 7, 6109-6117.

42 B. Liu, H. Q. Yang, L. C. Ning, H. Zhao, C. J. Zhang and S. Z. Liu, Phys. Chem. Chem. Phys., 2015, 17, 13280-13289.

43 Y. Chen, H. Zhao, B. Liu and H. Q. Yang, Appl. Catal., B, 2015, 163, 189-197.
44 S. P. Harimkar and N. B. Dahotre, J. Appl. Phys., 2006, 100, 024901.

45 J. J. Versluijs, M. Bari, F. Ott, J. M. D. Coey and A. Revcolevschi, J. Magn. Magn. Mater., 2000, 211, 212-216.

46 J. L. Costa-Krämer, N. García, P. García-Mochales, P. A. Serena, M. I. Marqués and A. Correia, Phys. Rev. B: Condens. Matter Mater. Phys., 1997, 55, 5416-5424.

47 S. O. Kasap, Principles of Electronic Materials and Devices, McGraw-Hill, New York, 2006, vol. 3, p. 464.

48 X. F. Duan, Y. Huang, Y. Cui, J. F. Wang and C. M. Lieber, Nature, 2001, 409, 66-69.

49 S. Chu, G. P. Wang, W. H. Zhou, Y. Q. Lin, L. Chernyak, J. Z. Zhao, J. Y. Kong, L. Li, J. J. Ren and J. L. Liu, Nat. Nanotechnol., 2011, 6, 506-510. 